\title{
Correction to: An introduction to the modeling of active fault zone width's efect on the qualitative deformation of lifelines and their routing (case study: buried gas pipelines in east of Iran)
}

\author{
Babak Kheradmand ${ }^{1} \cdot$ Behnam Rahimi $^{1} \cdot$ Nasser Hafezi Moghaddas $^{1} \cdot$ Majid Mehrizi $^{2}$
}

Published online: 5 September 2021

๑) Springer-Verlag GmbH Germany, part of Springer Nature 2021

\section{Correction to: Environmental Earth Sciences (2021) 80:397 https://doi.org/10.1007/s12665-021-09481-1}

In the caption of Fig. 8 the source information of the Fig. 8 is missing in the original publication. The correct caption of Fig. 8 is given below:

Schematic diagram describing the fault zone and the extent of the damaged areas. (source: Fig. 1 of the article: Anita Torabi, Silje Støren Berg (2011) Scaling of fault attributes: A review, Marine and Petroleum Geology, Volume 28, Issue 8, https://doi.org/10.1016/j.marpetgeo.2011. 04.003.)

We regret the inconvenience caused.

The original article can be found online at https://doi.org/10.1007/ s12665-021-09481-1.

Behnam Rahimi

b-rahimi@um.ac.ir

Babak Kheradmand

babak.kheradmand@mail.um.ac.ir

Nasser Hafezi Moghaddas

nhafezi@um.ac.ir

Majid Mehrizi

mmehrizi@yahoo.com

1 Department of Geology, Ferdowsi University of Mashhad, Mashhad, Iran

2 Head of Mechanical Engineering at Iranian Gas Engineering and Development Company, Tehran, Iran
Publisher's Note Springer Nature remains neutral with regard to jurisdictional claims in published maps and institutional affiliations. 